\title{
THE SYLLABLE STRUCTURE OF TIV
}

\author{
Dr. (Mrs.) Elizabeth Ugechi ${ }^{1}$ and Francis Iorchia Ayagah ${ }^{2}$ \\ ${ }^{1}$ Department of Languages and Linguistics, Benue State University Makurdi \\ Email. elizabethugechi@gmail.com \\ ${ }^{2}$ Department of Languages and Linguistics, Benue State University Makurdi \\ Email. talk2ayagah@gmail.com
}

\begin{abstract}
Cite this article:
Elizabeth U., Francis I.A. (2021), The Syllable Structure of Tiv. International Journal of Literature, Language and Linguistics 4(1), 53-63. DOI: 10.52589/IJLLL-

P2UNAMBU.
\end{abstract}

\section{Manuscript History}

Received: 17 Aug 2021

Accepted: 13 Sept 2021

Published: 22 Sept 2021

Copyright $\odot 2020$ The Author(s). This is an Open Access article distributed under the terms of Creative Commons AttributionNonCommercial-NoDerivatives 4.0 International (CC BY-NC-ND 4.0), which permits anyone to share, use, reproduce and redistribute in any medium, provided the original author and source are credited.
ABSTRACT: Linguistic studies reveal that every language has a particular way of combining its sounds to form words or parts of words called syllables. The paper looks at the syllable structure of the Tiv language, one of the Bantoid languages spoken mostly in the Middle Belt area of Nigeria, especially in Benue, Plateau, Taraba, Nasarawa and Cross River states of Nigeria. The objective of the study is to investigate the internal structure of syllables in the Tiv language in order to establish the regularities and restrictions inherent in the language. The study, therefore, aims at ascertaining the syllable patterns that are found in Tiv. This study adopts qualitative and analytical research design using the $C V$ tier model of the phonological theory of syllable analysis as proposed by McCarthy (1979) and adopted by Clements and Keyser (1983), to explicate the permissible patterns of syllable structures in Tiv. Data for the study were gathered from native speakers of Tiv, whose language has not been corrupted by urbanisation and the researchers' intuitive knowledge of the Tiv language. It was found out in the study that, some of the permissible syllable structures in Tiv language include vowels and consonants like $v, c v, c c v, c c c v, c v c$. It was also discovered that all the five vowels of the English alphabets may begin or end a syllable in the Tiv language. As found in English and other languages where the sequential occurrence of two or more consonants is termed consonant cluster, the Tiv syllable structure permits two or more consonants at the initial or final positions of the syllable which could occur as onset or coda, but they are not regarded as consonant clusters. They are regarded as coarticulations. The study concludes that Tiv language has a wide range of phonotactic constraints which if studied can contribute to the development of Tiv language.

KEYWORDS: Tiv Language, Syllables, Nigeria 


\section{INTRODUCTION}

Linguistic studies reveal that every language manifests a particular way of combining its sounds to form meaningful words or parts of words, called syllables. Each language puts certain restrictions on these possible combinations. For example, in English consonant sequences like ngyu, gyw or yw are not permissible at a word-initial position. When we analyse what restrictions (and regularities) are found in the language under study, we are studying the syllable structure of that language. This paper, therefore, sets to investigate the internal structure of the Tiv language in order to establish the restrictions/constraints and regularities inherent in it. The aim/s of this study is to: ascertain which syllable patterns are found in Tiv language and how they are formed. Investigate the constraints or rules that govern the formation of these patterns. Examine the effects of violating the constraints or rules of combinatoriality of phonemes in the structural configuration of syllables. Verify the importance of the knowledge/awareness of syllable structure in morphophonemic and morphosyntactic analysis.

\section{REVIEW RELATED LITERATURE}

The concept syllable has faced a range of arguments in defining its place in the phonological theory. Initially, it was understood only at surface level with syllable features glossed over with little theoretical argument and "generalizations pertaining to segment sequencing, referring to morphological constituents alone" (de Lacy, 2007:174).

Assumptions about the syllable grew with its role on general phonological significance discussed. These assumptions as observed by Kahn, (1976:20) are that:

there exists on the phonetic level a well-defined unit of perception and production larger than the segment and smaller than the word, and (...) this unit plays a very significant role in conditioning distributional statements, sound changes, synchronic phonological rules, etc.

This unit is of course the syllable. With an increasing need for languages to account for the constraints on segmental distribution, the domain of phonotactics was posited with the syllable being recognized. These developments led to the syllable being defined as a unit of representation governed by the principles of segment sequencing (Kahn, 1976).

(Goldsmith, 2011) discusses the use of rules to account for syllable structure. He holds that rule-based accounts of the syllable are focused on the preservation of syllable structure. He further contains that the only obligatory component, cross-linguistically, was the nucleus with the presence or absence of the remaining two, the onset and the coda, being language-specific; this implied that a syllable inventory is language-specific. The internal structure of the syllable is hierarchical with an onset $(\mathrm{O})$ and rhyme. The rhyme is made up of the nucleus $(\mathrm{N})$ and the coda. In most languages, the onset and coda positions are filled with consonants while the nucleus will have either a vowel or a syllabic consonant (Keyser 1983).

Another view which focuses on peaks and margins of syllables uses the sonority of segments to understand the concept of the syllable. Segments are ordered starting from those with high sonority (vowels) down to those with the least sonority (obstruents). The nucleus generally has 
sounds with the highest sonority with the position of sounds in a syllable based on sonority guided by the Sonority Sequencing Principle. The principle states that sonority rises to the nucleus followed by an inevitable drop thus constraining the positions that sounds can occupy in the syllable.

Itoro (2001) says that in every language, words are divided into a sequence of pronounceable units called syllables. According to him, a syllable is made of two elements. These are ' $\mathrm{C}$ ' and ' $\mathrm{V}$ '. The ' $\mathrm{C}$ ' element represents the consonant and is positioned at the initial and final margins of the syllable structure. The initial margin is the 'onset' while the final margin is the coda. The ' $\mathrm{V}$ ' element on the other hand represents the vowel or any other syllabic consonant, which 'typically constitutes the peak of the syllable and occupies the 'nucleus of the syllable. All languages have the core $\mathrm{C} \mathrm{V}$ syllable structure irrespective of the complexity of a language. Languages have different syllable structures with varying syllable inventories. In terms of the $\mathrm{C} \mathrm{V}$ structure, some languages have only the core syllable $\mathrm{C} \mathrm{V}$ while others have a very complex structure with an extensive inventory.

Maddieson (2001) classifies the structural complexity of the syllable structure of languages based on their amount of inventory into three categories. These include simple, moderately complex and complex syllable structures. Table 1 illustrates the amount of inventory of each category.

\section{Table 1}

\begin{tabular}{|l|l|l|}
\hline s/no & description & Selected examples \\
\hline 1 & Simple syllable structure & C V \\
\hline 2 & Moderately complex syllable structure & (C) C V C \\
\hline 3 & Complex syllable structure & (C) (C) (C) V (C) (C) (C) (C) \\
\hline
\end{tabular}

In view of the above categorization, it could be argued that the Tiv syllable possesses a moderately complex syllable structure, without consonant clusters. The onset constituent of the Tiv syllable structure is occupied by monograph and digraph, trigraph or hectograph while the final margin is occupied basically by nasal consonants $/ \mathrm{m} /, / \mathrm{n} /, / \mathrm{y} /$, the liquid consonant $/ \mathrm{r} /$, the lateral sound $/ 1 /$ and the voiced labio-dental fricative $/ \mathrm{v} /$.

\section{Theoretical framework.}

Many theories attempt to provide an explanation or definition of the syllable. Most of these explanations or definitions are phonetically and phonologically based. For a phonetic definition, two theories (prominence and chest pulse theories) have been proposed by linguists (Itoro, 2011).

\section{The prominence theory.}

This theory is based on auditory judgment. It argues that in a given string of sounds, some are louder than others. Sounds that are naturally very loud are vowels and syllabic consonants, which are produced without or less constriction in the air passage while less sonorous sounds are produced with constriction in the air passage and are basically consonants. 
Given the characteristic loudness of the sound, vowels rank highest in sonority. The loudness of a sound is measured on the scale of hierarchy as follow:
Vowels
Low
Mid
High
Glides$$
/ \mathrm{j} /[+ \text { front, }- \text { round }], / \mathrm{w} /[- \text { front, }+ \text { round }] \text {. }
$$
liquid
$/ \mathrm{r} /$

\section{Obstruent Fricatives Affricates Stops (Goldsmith, 1990:111)}

The basic tenet of this theory is that the number of syllables per word is determined by the number of peaks of sonority. For instance, the English word 'nationality /nei.fa.na.li.ti/ counts five syllables because it counts five peaks of sonority.

The arguments of this theory sound very appealing but do not help in discussing the syllable structure of Tiv words. For instance, the word 'mfe consists of two syllables ( $\mathrm{M}$ and fe) although it has only one vowel. The definition of the syllable as given by this theory does not apply to the Tiv syllable since the measurement of the degree of the sonority of sounds in Tiv is not an easy task.

\section{The chest pulse theory}

This theory defines the syllable in the context of muscular activities and lung movement. The theory views the syllable as the activity of respiration, which is identified by a pulse in the breath. The syllable is thus, defined by the theory as a reinforced chest pulse. Each syllable is produced according to the type of articulation that is involved, the overall vocal efforts and the habit of an individual speaker. The theory argues that the number of chest pulses accompanied by the increase in the air pressure determines the number of syllables to be produced, thus allowing to associate syllables with chest pulses (Laver 1994 and Maddieson 2001). This approach cannot account for cases in Tiv syllable where two vowels, in some instances, cooccur in one place to form a syllable as in aa.ven (stages or times), aase (cheeks)

\section{Phonological theory.}

This theory holds that a syllable has constituent parts. It explains that a syllable (conventionally marked as small Greek sigma $\boldsymbol{\sigma}$ ) has two immediate constituents. These include the onset $(\mathbf{O})$ and the rhyme (R). The onset consists of the consonant(s) which precedes the nucleus in a syllable structure while the Rhyme is the second part of a syllable which consists of the vowel acting as the nucleus of the syllable and any other accompanying consonantal element. The rhyme in turn is divided into two constituents - the nucleus or peak represented by ' $N$ ' and the coda represented by the symbol $\mathbf{C}_{\mathbf{0}}$. The peak represents the nucleus and the most loudly heard part of a syllable while the Coda is any consonantal element that follows the nucleus and which, provides the final margin of the syllable.

This paper adopts phonological definition or explanation of the syllable taking into cognizance, the fact that the approach is centred on specific functional definitions based on particular languages. We thus view the syllable as a hierarchical structure represented by the means of a tree diagram. The model of the phonological approach we have adopted for this paper is the $\mathrm{C} \mathrm{V}$ tier approach, which considers the syllable as a three-tiered structure consisting of the syllable $(\boldsymbol{\sigma})$, the $\mathrm{C} \mathrm{V}$ and the segmental tiers. 
The C V tier approach of syllable analysis which was proposed by McCarthy (1979) was adopted by Clements and Keyser (1983). It is a universal theory; a component of syllable representation regardless of its functioning in the word-formation component. The proponents of this approach argue that $\mathrm{C}$ and $\mathrm{V}$ are not variables belonging exclusively to the vocabulary of phonological description but entities of formal phonological representation separate from consonants and vowels and arranged on separate tiers as shown below.

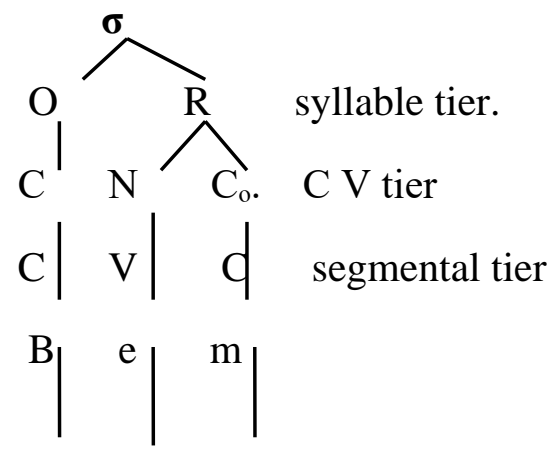

The $\mathrm{C} \mathrm{V}$ tier and segmental tier are dominated by the syllable node represented by $\boldsymbol{\sigma}$. The syllable $(\boldsymbol{\sigma})$ projects onto Onset $(\mathbf{O})$ and Rhyme $(\mathbf{R})$. The Rhyme projects into Nucleus $(\mathrm{N})$ and Coda $\left(\mathbf{C}_{\mathbf{0}}\right)$, which in turn dominates $\mathrm{C} \mathrm{V}$ tier as an intermediary between the syllable and the segments. The basic justification of this approach is that it specifies the parameter, along which languages vary in the choice of syllable types (Itoro 2011).

\section{METHODOLOGY}

This paper adopts a qualitative and analytical research design. The instruments of data collection for the study include the intuitive phonological ability of the researcher as a native speaker of the language. The researcher also orally interviewed competent native speakers, linguists, academics and other critical stakeholders of the Tiv language. Because Tiv is a homogenous language this study covers only Tiv speakers in Benue state. The study did a purposive sample of 150 competent native speakers who were deemed proficient in the language. These include 50 adult or elderly speakers, 20 clergymen, 50 academics as well as 30 members of the Tiv Language Studies and Development Association (TLSDA). The rationale behind the choice of these persons is that they are believed to be competent native speakers who possess an appreciable level of proficiency and competence in the language. The presentation of data is done in tables and the study employs phonological theory for analysis

\section{Inventories of Tiv syllable structure}

Tiv adopts and augments its syllable from the universal basic inventories $(\mathrm{CV}, \mathrm{VC} \mathrm{V}$, and $\mathrm{C}$ VC). Tiv has nine possible syllable structures. These structures are as follows: 
1. V - Shape:

This syllable structure consists of a vowel which is constrained to the following vowels /i u/. Any of the vowels can constitute a syllable when;

(a) It occurs independently as a phonological word functioning as a pronoun or preposition.

(b) When it occurs at the initial position in the majority of Tiv words. Examples
A va
he/she it has come
A.baver
news
I tindi un
$\mathrm{He} /$ she is sent
A.tindi
laws
U ya?
Have u eaten?
I. bya
sack

\section{N-Shaped:}

This type of syllable structure consists of the syllabic nasal $/ \mathrm{m} /$ which is homorganic with the following consonant. The consonant $/ \mathrm{m} /$ sometimes appears independently as a phonological word when it functions as a first-person singular pronoun. It generally functions as a syllable when it appears at an initial position in any word except when it precedes the bilabial plosive sound $/ \mathrm{b} / . / \mathrm{m} /$ also constitutes its syllable when it occurs at the final position in Tiv words where it functions as an objective case form of the personal pronoun or the possessive pronoun. Examples
m. ngu van I am coming
m.tem sitting.
m.yom salvation

\section{VV-Shape}

This is a syllable structure in which two vowels co-occur as a unit. It does not contain a consonant at the initial or final margin. Examples
aa.
Scratch
ie
lie
aa,
persist
oo.
Sunshine

\section{CV - Shape:}

Like any other language in the world, CV syllable structure in Tiv is the most widely and commonly used. It either functions as a phonological monosyllabic word or part of a word. It does not contain a coda, thus it can be described as an open syllable. Examples 


$\begin{array}{ll}\text { Ti. } & \text { Name } \\ \text { De } & \text { Stop } \\ \text { Ga. } & \text { Not }\end{array}$

Ngu. Is around/available.

\section{VC - Shape:}

This syllable structure contains a coda but does not bear onset. It is a phonological word on its own and sometimes part of a word in Tiv as shown below:

$\begin{array}{ll}\text { Ir } & \text { dirt } \\ \text { il } & \text { Black } \\ \text { or. } & \text { Man } \\ \text { iv } & \text { theft } \\ \text { er } & \text { do or perform } \\ \text { Un } & \text { Him, it or her }\end{array}$

6. VVC - Shape:

This is a syllable consisting of a cluster of vowels or long vowels at the initial position and a consonant at the final margin. The consonant at the final margin of this is restricted to nasals and the voiced Labio Dental fricative /v/ as in:

iin. (He, She, It) Steals

oon. (He, She, It) swims or breathes.

Eev. mace graven image

\section{7. $\quad$ C V V}

This syllable can be described as heavy. It is open and contains a consonant at its initial margin, a cluster of vowels or long vowels in the nucleus and a Zero consonant at the coda. The long vowel here is found in monosyllabic words like:
kaa (Tell)
too (Take)
cii (All)
bee (finish) 


\section{8. $\quad$ CVC - Shape:}

It is a syllable structure that is heavy. It is made up of an initial consonant, a vowel as its nucleus and a final consonant. It is a closed syllable structure. The coda position is restricted to the sonorant $/ \mathrm{m}, \mathrm{n}, \mathrm{ng}, \mathrm{r}, \mathrm{l} /$ and the voiced Labio dental fricative /v/. Examples are as follows

Bam - bank, to provoke a person

Gbem - always, forever

Gbyang - intensity or degree of how something hits the ground

Byan - Lack

\section{CVVC - Shape}

The composition of this syllable structure is an initial consonant, a cluster of vowels or long vowels and a final margin consonant. Examples of this syllable structure include;

Taav tobacco

Teen sells

Byaang very red

\section{THE INTERNAL STRUCTURE OF THE TIV LANGUAGE}

Maddieson (2011) and Itoro (2011) held that the internal structure of the syllable often consists of one or more onsets accompanied by the nucleus and zero or more coda. The nucleus, generally referred to as the peak of the syllable, is the only obligatory element of the syllable.

Languages have varying internal structures, though the structural dimension of the syllable into onset and rhyme and further division of rhyme into nucleus and coda may have universal application. The assignment of segments into these constituent parts is language-specific. For instance, the internal structure of the onset varies from language to language while some assign one consonant segment to the onset; others assign as much as three or four. Itoro (2011).

Given the varying internal structures of languages, many approaches have been proposed. Blevis (1994) cited in Itoro (2011) summarises these approaches as follows;

a. Flat structure (zero sub-constituents)

b. Moral approach 6 - Cou (i.e weight of syllable determined by the number of morae)

c. Binary grouching with body: 6 - Body-----Onset

d. Ternary grouching 6 - onset nucleus coda

e. Binary brauching $\sigma$ - onset rhyme; $\mathrm{R}=$ nucleus coda

We adopt in this paper the number (E) for the description of the Tiv internal structure. 


\section{THE TIV ONSET}

As earlier pointed out in this paper, the Tiv onset has a moderately complex syllable structure without a consonant cluster. The onset constituent of the Tiv syllable is made up of a single consonant segment or complex segments which are counted phonologically as single segments, but which have internal structures comparable to sequences of segments (clusters). Clements and Keyeser (1983), Maddieson (2011) and Itoro (2011) pointed out that the CV tier approach of the autosegmental analysis enables these segments to be characterised between a single element of the CV tie and sequence tiers as shown below.

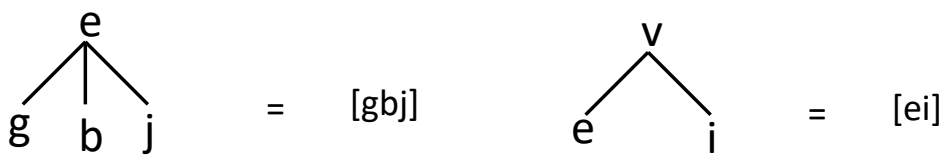

The data at the disposal of the researcher indicate that Tiv has a total of 50 co-articulations. Out of these, forty usually occupy the onset position thus forming the complex internal structure of the Tiv onset.

We adopt the argument by Itoro (2011) that co-articulation consonants are not clusters because:

i. They are inseparable under a process like reduplication. Example, gyan-gyan /gjæn gjæy/ - Iron-shirt.

ii. No morphological process can alter one of the segments without altering the other in the sequence.

iii. These segments contrast with an otherwise bi-segmental sequence. Example

$$
\begin{array}{ll}
\text { ga }- \text { not } & \text { gba }- \text { fall } \\
\text { ba: }- \text { additive } & \text { gba: }- \text { branch }
\end{array}
$$

iv. The segments are characterised in terms of one too many relationships and not one to one relationship.

v. These segments are produced with shared simultaneous application of articulations and there is no blocking in the transition from $1^{\text {st }}-2^{\text {nd }}$ segment. Our onset in the word gbyang is as follows:

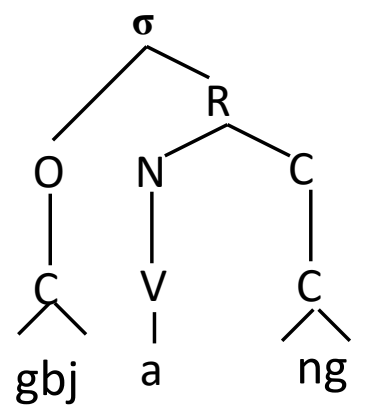




\section{TIV NUCLEUS}

The structure of the Tiv nucleus is either simple or complex. When simple, it consists of only one vowel as ' $\mathrm{m}$ ' ' $\mathrm{u}$ ' ' $\mathrm{i}$ ', but when complex, it is made up of a diphthong or long vowel (which in Tiv is morphologically represented by doubling the vowel), as oo, er, ie The complex nucleus structure of the Tiv syllable divides into adjoining sisters and immediately dominated by $\mathrm{N}$ as shown below.

$\begin{array}{llll}\text { Simple } & \mathrm{N} & \text { Complex } \\ \text { nucleus } & \mathrm{V} & \bigwedge_{(\mathrm{V}) 2}^{\mathrm{n}} & \end{array}$

Itoro (2011) held that a constituent with one nucleus is light syllable while one with more than one nucleus or branching rhyme is heavy

\section{TIV CODA}

The Tiv coda has a very simple structure. It permits only one consonant restricted to the sonorants /m, n, ng, r, 1/ and the voiced Labio dental fricative /v/. Because of this restriction, Tiv coda is generally heavy.

\section{TIV WEIGHT STRUCTURE}

A syllable is said to carry weight when it has a branding rhyme. That is it contains a final consonant or a branding nucleus. Out of the nine possible syllable structures in Tiv, six are heavy. These include:

(i) V V - Shape (ii) VC - Shape, (iii) VVC - Shape (iv) CVV - Shape (v) CVC - Shape and (vi) CVVC - Shape.

These Tiv syllable structures are heavy because:

a. They consist of a branching rhyme

b. Some of them are closed syllables with sonorants and voiced labiodental fricative V.

\section{CONCLUSION}

This paper gives insight into the internal structure of Tiv. The paper portrays that Tiv possesses a moderately complex syllable structure with (C) CVC without consonant clusters. It is evident from the analysis that the syllable is very important in phonological analysis. It is unarguable 
that, phonological processes occur within syllables and across syllable boundaries. The combination of syllables to form words triggers phonological processes, and also, analysis indicates that the phonotactic constraints of Tiv language force the sequence of words in syllables to concur with the acceptable order of languages. We conclude that the knowledge/awareness of syllable structure is indispensable in morphosyntactic and morphophonological analysis because many phenomena which are relevant to these areas cannot be properly understood unless the segment is involved. After all, certain structures are so abstract to the point that they cannot be properly understood by definition or pronounced directly in way segments do.

\section{REFERENCES}

Blevins, J. 1995. The syllable in phonological theory. In John A. Goldsmith (ed.), The handbook of phonological theory. J. Goldsmith. Ed. Oxford: Blackwell. 206-44.

De Lacy, P. (ed) 2007. Structure. The Cambridge handbook of phonology. Cambridge: CUP.

Essien O.E. (1990). A grammar of the Ibibio Language. Ibadan: university press.

Goldsmith, J. (1990). Autosegmental and Metric phonology. Oxford: Blackwell.

Kahn, D. (1976). Syllable-Based generalization English phonology. PhD Dissertation. Published 1980.Newyork: Garland.

Keyser, J. (1983). CV phonology: Historical Background. http://www.mit.ed.people/keyser/index.html. retrieved 2/20/2021.

Laver, John. 1994. Principles of phonetics. Cambridge: Cambridge University Press.

MacCarthy, J. (1979). Formal problems in Semitic phonology and morphology. PhD Dissertation, University of Edinburg.

Maddieson, Ian. 2011. Phonological complexity in linguistic patterning. In Proceedings of the 17th International Congress of Phonetic Sciences, Hong Kong, August 17-21. 28-34.

Michael, I (2011). The internal structure of the Anaang syllable. Journal of institute for Nigerian languages, university of Nigeria, Aba campus. NILAS Vol. 2 No. 2

Michael, I. (2009). Syllabification in Anaang. Usem. Journal of linguistics, language and literature vol 2. 38-48

Michael, I. (2009). The syllable structure of anaang language. Unpublished PhD dissertation. University of Ibadan. 